\title{
Father and Daughter Relationship and Its Impact on Daughter's Self-Esteem and Academic Achievement
}

\author{
Asbah Zia \\ Department of Psychology, University of Karachi, Karachi- Pakistan, \\ Visiting Faculty at Sir Syed University of Engineering and Technology \\ Email: asbahzia@gmail.com \\ Dr. Anila Amber Malik \\ Associate Professor, Department of Psychology, University of Karachi , Karachi- Pakistan \\ Email anila_ahsen@hotmail.com \\ Saima Masoom Ali \\ Lecturer, Department of Psychology, University of Karachi Karachi- Pakistan \\ Email: saima.ghabrani@gmail.com
}

Doi:10.5901/ajis.2015.v4n1p311

\section{Abstract}

Present study examined the father and daughter relationship and its impact on daughter's self-esteem and academic achievement. Sample is comprised of total 321 unmarried adolescent girls aged 13 to 21 whose fathers are alive and they are living together. The Quality of Relationship Inventory, Rosenberg self-esteem scale were used to measure quality of fatherdaughter relationship and self esteem. Academic achievement was assessed through participant's reporting on demographic sheet. It was a survey design, participants were asked to fill the above mentioned battery of tests including demographic sheet and researcher remained there to answer any query. For the analysis of results, descriptive and inferential statistics were carried out. The correlation between quality of Father-Daughter relationship with self esteem, academic achievement, found significant at 0.01 alpha level.

Keywords: Father and daughter relationship, Self-esteem, Academic achievement, adolescent girls, Quality of Relationship.

\section{Introduction}

The behavior of father is very important to shape child personality and modify his/her behavior. According to recent researches on teenage daughters, they and their fathers never get to know one another as well than to their mothers and how much they spend time with their mother to talk her comfortably they usually don't spend time with their fathers. They don't know that father is also equally important like mother in daughter's psychological health, self confidence, their school achievement, intimate relationship and also in and her job and income in future. Achievement of female and getting success in male dominated fields i.e., mathematics is largely dependent upon the amount of time, guidance and support she got received from the father. Support of fathers may have especially importance for his daughters since he can serve as a clear counterforce to prevent male biases (Biller, 1993).

Self-esteem develops when father encourages his daughter to be the best that she can be, rather than make her feel worthless or weak. When daughter doesn't get encouragement and support on their work and activities or make them feel that their play is silly or stupid etc, she may develop sense of guilt which can directly affect her self esteem and self worth, more so, she may develop unrealistic doubts on her capabilities and these feelings of guilt and doubts may persist throughout her life. Every father has a power in his daughter's life that mother just doesn't have, he could be responsible for boosting up or lower level of her self-esteem and self-confidence (Dunlop, Burns, \& Berminghan, 2001).

Olweus (1993) found that weak temperament and negativism in the father was associated with child victim-prone behavior in their peer group and other social situations. Fathering is of course difficult task for men, especially with their daughters because this is the relationship that requires more softens caring and intimacy and most of the men cannot handle it. 


\section{Literature Review}

Daughters get to know how to get along with their husbands, friends, boyfriends and other relations after getting along with father and brother. Problematic relationships with men, depressive symptoms or low level of self-esteem are often the residue of a father's desertion. When children grow up those having feeling of closeness with their fathers in the period of adolescence, they are more likely to develop a healthy and satisfied adult marital relationship (Flouri and Buchanan, 2004).

Security is obviously has very much importance for all humans but for the girls it is vital for growth (Griffin, 1998) and if this security or protection she gets from father's side, it enables daughter to thrive in relative safety, increasing their chances to grow into a healthy adult (Elium \& Elium, 1994). Healthy father-child relationship is highly correlated with the absence of emotional and behavioral difficulties in the age period of adolescence and higher academic motivation (Flouri and Buchanan, 2002). Study conducted by Li and Seltzer (2005), found the poor relations between father and daughters badly affects on daughters' self-esteem.

Absence of father may produce many difficulties in the learning process of a child. Many studies showing that girls with absent or uninvolved fathers usually show poor school performance, IQ scores and achievement test scores on lower level and impaired cognitive development, (Grimm-Wassil, 1994). With good quality of self esteem and confidence children are able to achieve good educational grades and they consider as competent students. Many researchers have determined the youth's better self esteem and academic advancement in response to good family environment and quality of parent-child relationship (Adedokun \& Balschweid, 2008).

It is an effort to develop an insight about the reality that father-daughter relationship does have considerable and long-lasting impact on daughters. Moreover, the quality of their relationship is associated with many of the most troubling problems with daughters including poverty, lower education, psychological problems, lower level of self esteem and confidence, poor interpersonal relations and even divorce etc.

A study conducted by the U.S. Department of Education found that children of highly involved fathers were 43 percent more likely to get mostly A's than other children. Another study by government concluded that daughters with supportive and actively involved fathers are twice as likely to stay in school, have higher intellectual functioning, higher quantitative and verbal skills. Many researches show that Fathers have also been proven to help children become more achievement-oriented, more successful and more competent. Like in a study of Pedersen, Anderson, \& Kain, (1980) children whose fathers show great involvement with them, were more competent cognitively at 6 months of age and achieved high scores on Bayley Scale of Infant Development.

\section{Methodology}

\subsection{Objective}

Present study is designed to investigate father and daughter relationship and its Impact on daughter's Self-Esteem and Academic Achievement.

Study would examine Positive father and daughter relationship and its impact Self-esteem of Daughters.

Study will assess relationship between Positive father and daughter and academic achievement of daughters

Present study aimed to investigate the effect of this relationship of father and daughter on daughter's Psychological Growth. For this purpose following hypotheses were formulated.

1- "Positive father and daughter relationship will facilitate the high self-esteem of daughters".

2- "Positive father and daughter relationship will facilitate the academic achievement of daughters".

Survey design utilized for the present study, as standard measures are available to measure the variables of study. Secondly survey method takes less time and participants also find it convenient to rate their feelings on statements.

\subsection{Sample}

Total number of 321 unmarried adolescent girls aged 13 to 21 whose fathers are alive and they are living together were taken as a sample. All of them were from different socioeconomic status. 


\subsection{Measures}

i) The Quality of Relationship Inventory (Gregory R. Pierce, 1990) Assessing the Interpersonal Context of Social Support. It contains 25 items having 4-point rating scale ranging from $1=$ Not at all, to $4=$ Very much.

ii) The Self-esteem scale (Rosenberg 1965) is very brief and self-administering, measures of self-esteem, and takes at most five minutes. Having ten items which is answered on a four point scale from strongly agree to strongly disagree,

\section{Procedure}

The researcher approached unmarried adolescent girls aged between 13 to 21, from different socioeconomic status, whose father are alive and they are living together. Through a battery of tests with demographic sheet, data was collected. After administering informed consent and demographic sheet they were given battery of tests including the Quality of Relationship Inventory, Rosenberg self esteem scale. In order to find out academic achievement participants were asked to mention GPA. Researcher remained there if participants had any query related to tests. After that their responses were scored and data was gone through from statistical analysis.

\section{Results}

Table I - Descriptive Statistics of Quality of Relationship Inventory and Self Esteem

\section{Descriptive Statistics}

\begin{tabular}{|c|c|c|c|}
\hline & Mean & Std. Deviation & $\mathrm{N}$ \\
\hline QRI & 43.12 & 7.601 & 321 \\
Selfesteem & 23.16 & 5.830 & 321 \\
\hline
\end{tabular}

Table I: illustrates the descriptive values of Quality of Relationship Inventory (Social support and depth score) and Self esteem.

Table II - Correlation between Quality of Relationship Inventory with Self Esteem

\begin{tabular}{|ll|l|l|}
\hline \multicolumn{2}{|c|}{ Correlations } \\
\hline QRI & Pearson Correlation & QRI & Selfesteem \\
& Sig. (1-tailed) & 1 & $.763\left(^{* *}\right)$ \\
Self esteem & & .000 \\
& $N$ & 321 & 321 \\
& Pearson Correlation & $.763(* *)$ & 1 \\
& Sig. (1-tailed) & .000 & \\
& $N$ & 321 & 321 \\
\hline
\end{tabular}

Table II: illustrates the positive correlation between positive father and daughter relationship with self esteem. 
Correlation between Quality of Relationship and Daughter's Self-Esteem.

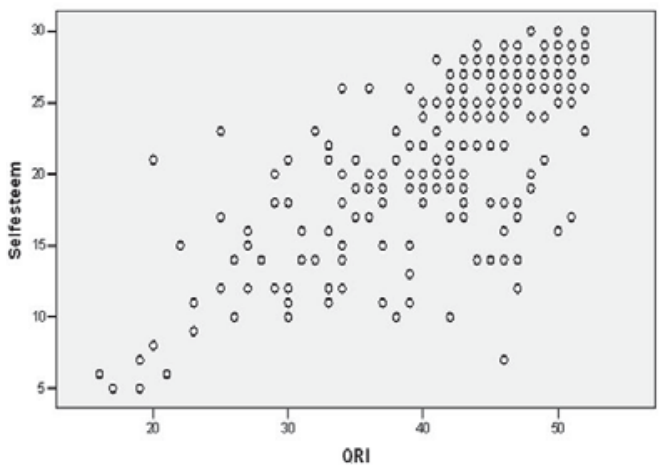

Graph shows the positive correlation between Quality of Relationship and Ser-Esteem

Figure I

Table III - Descriptive Statistics of Quality of Relationship Inventory with Academic Achievement

\section{Descriptive Statistics}

\begin{tabular}{|c|c|c|c|}
\hline & Mean & Std. Deviation & $\mathrm{N}$ \\
\hline QRI & 43.12 & 7.601 & 321 \\
Academic Achievement & 4.80 & .963 & 321 \\
\hline
\end{tabular}

Table III: illustrates the descriptive values of Quality of Relationship Inventory (Social support and depth score) and Academic Achievement of daughters.

Table VI - Correlation between Quality of Relationship Inventory with Academic Achievement

\begin{tabular}{|c|c|c|c|}
\hline \multicolumn{4}{|c|}{ Correlations } \\
\hline & & SSDS & Academic Achievement \\
\hline$\overline{Q R I}$ & $\begin{array}{c}\text { Pearson Correlation } \\
\text { Sio (1-tailed) }\end{array}$ & 1 & $\begin{array}{c}.522(* *) \\
000\end{array}$ \\
\hline & $\frac{N}{N}$ & 321 & 321 \\
\hline Academic Achievement & Pearson Correlation & $.522(* \star)$ & 1 \\
\hline & Sig. (1-tailed) & .000 & 321 \\
\hline
\end{tabular}

Table Vl: illustrates the positive correlation between positive father and daughter relationship with academic achievement of daughters.

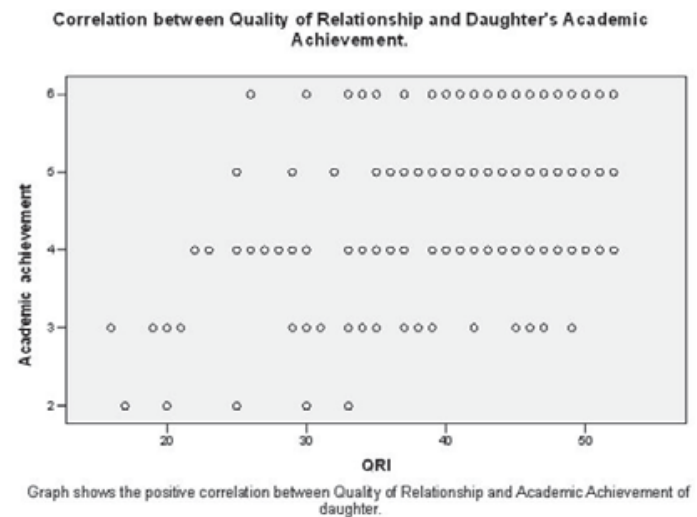

\section{Figure II}




\section{Discussion}

Involvement of father in her daughter's life shapes her self-image, self-esteem, confidence and helps her to achieve her goals. Involvement of father is an essential component in developing the daughter's self-esteem and positive self-image. Being in her life, being sensitive and alert towards her feelings, having time to listen to her, showing interest in her hobbies and verbal approval or praise are very crucial factors for building her positive self-esteem and self-image. With these all active and involved actions a girl may take help to eliminate her insecurities and can become a confident and challenge-taker lady. Usually Father's life serves as an impressive example in her life and she tries to view the world according to that perspective. The quality of time together between father and daughter is essential at all stages throughout her life.

A father needs to spend time with his daughter, should take care of her physical and psychological needs and should support her mother to bring up the daughter in a well manner.

The study is comprised of two hypotheses, for the first, (i) "Positive father and daughter relationship will facilitate the high self-esteem of daughters", has been accepted as our result supports it that when father and daughter relationship is positive or supportive it will lead to higher self esteem of daughters. Result shows 0.763 correlation coefficient which is significant at the 0.01 level (see table II). Self esteem is our self pride and it is a component which is very essential for developing a self loving personality, a person who knows his/her potentials and trusts upon his/her skills and abilities. Research discovered that well-fathered daughters are generally more self-reliant, more self-directed, more self-confident, and more successful in school and in their professional life (Nielsen, 2007). Daughter's self-esteem is greatly affected by the relationship with her father. Usually if a daughter has poor or low self esteem, it may be because her father was not around, or was not a good parent as he should has been. If she has high self esteem, likely that her father was a present in her life and supportive too. Children whose fathers are more involved in their lives are more satisfied with their lives (Eggebean \& Knoester, 2001), and they usually exhibit greater psychosocial maturity (Snarey, 1993 \& Pleck, 1997), and are likely to feel less psychological distress (Gove \& Mongione, 1983; Ozer', Barnett, Błennan, \& Sperling, 1998). If father is more loving, caring and affectionate - researchers predict - his daughter will be grow up as a more successful and smarter personality, and also less likely to be anxious, promiscuous and less likely to develop drug addiction. During the early years of life, daughters look to their fathers for love, admiration and reassurance. Several researches showed that positive presence of fathers is much important for their daughters to develop their self esteem and self confidence which are also supportive of our results.

The second hypothesis of this study was that "Positive father and daughter relationship will facilitate the academic achievement of daughters". The value of correlation coefficient is 0.522 at the 0.01 level which supports our hypothesis at moderate level (see table XI). A figure of father is very essential for academic approval and support, and a daughter usually respond negatively in academics areas without presence of father. Daughters of insufficiently available fathers are also more prone to get bad grades, drop out of high school or never arrive to college for further academics (Chadwick, 2002; Menning, 2006). It proves that a daughter's success in school or academic area has at least a little bit to do with having a father in her life. Many researchers agree the daughters who lacked involved father, are more likely to experience diminished cognitive development, lower achievement test scores, lower IQ scores or overall poor academic or school performance (Krohn \& Bogan, 2001). This study also noted that not having involved father may either discourage college attendance or force girls to attain the highest possible standards in an effort to get their father's missing approval. A solid foundation of this relationship with father is essential for success of daughters in both academics and career. Daughters without this foundation are more likely to give up easily and not carrying out if they start college at all. The influence of an involved father on academic achievement proceeds into adolescence and young adulthood. Many studies found that an active, supportive and nurturing style of fathering is highly associated with better academic achievement, intellectual functioning and verbal skills among adolescents (Goldstine, H. S. 1982). According to Pruett's study involved Fathers who are provide better nurturance and have playful nature are more likely to have children with higher Intelligence Quotient as well as better cognitive and linguistic capabilities (Pruett, K. 2000). Children reared under involved fathers are more likely to get higher levels of financial, educational, career and occupational achievement as they get better educational outcomes; they usually have higher educational expectations and attainment (Amato, 1994; Barber \& Thomas, 1986; Barnett, Marshall, \& Pleck, 1992).

\section{Conclusion}

Findings of the study show that father's participation plays significant role in daughter's self esteem and academic growth. 
Those fathers who take interest and actively participate in daughter's life, their daughters are likely to feel herself a worthwhile person and remain successful in academic life.

\section{References}

Adedokun, O.A. \& Balschweid, M.A.(2008). The Mediating Effects of Self-esteem and Delinquency on the Relationship between Family Social Capital and Adolescents' Educational Achievement. Educate,8 (1), pp.2-1.

Amato, P. R. (1994). Father-child relationships, mother-child relations, and offspring psychological well-being in early adulthood. Journal of Marriage and the Family, 56, 1031-1042.

Barber, B. K., \& Thomas, D. L. (1986). Dimensions of fathers' and mothers' supportive behavior: The case for physical affection. Journal of Marriage and the Family, 48, 783-794.

Barnett, R. C., Marshall, N. L., \& Pleck, J. H. (1992). Adult son-parent relationships and their associations with son's psychological distress. Journal of Family Issues, 13, 505-525.

Biller, H., (1993). Fathers a00 families: paternal factors in child development. Westport, CT: Greenwood Publishing Group, Inc.

Chadwick, L. (2002). Absent parents are more than money. Family Issues, 64, 661-665.

Dunlop, R., Burns, S., \& Berminghan, S. (2001). Parent child relations and adolescent self image following divorce. Journal of Youth and Adolescence, 30, 117-134. In Nielsen.L (2012) Father-Daughter Relationships: Contemporary Research and Issues. Routledge, Taylor \& Francis Group 711 Third Avenue New York, NY 10017.

Elium, J., \& Elium, D. (1994). Raising a daughter. Berkeley, CA. In Krohn. F.B., Bogan Zoe (2001) The effects absent fathers have on female development and college attendance. College Student Journal. http://findarticles.com/p/articles/mi_m0FCR/is_4_35/ai_ 84017196/pg_8/?tag=mantle_skin;content

Eggebean, D. J., \& Knoester, C. (2001). Does fatherhood matter for men? Journal of Marriage and the Family, 63, 381-393.

Flouri, E., \& Buchanan, A. (2002). What predicts good relationships with parents in adolescence and partners in adult life: Findings from the 1958 British birth cohort. Journal of Personality and Social Psychology, 16, 186-198.

Flouri, E. and Buchanan, A. (2004) Early Father's and Mother's Involvement and Child's Later Educational Outcomes. British Journal of Educational Psychology, 74, 141-153.

Griffin, D. (1998). Fatherless women. Los Angeles, California: Milligan Books. In Krohn. F.B., Bogan Zoe (2001) The effects absent fathers have on female development and college attendance. College Student Journal. http://findarticles.com/p/articles/mi_ mOFCR/is_4_35/ai_84017196/pg_8/?tag=mantle_skin;content

Grimm-Wassil, C., (1994). Where's daddy: how divorced, single and widowed mothers can provide what's missing when dad's missing. Overlook Press; ISBN 0879515414. In Krohn. F.B., Bogan Zoe (2001) The effects absent fathers have on female development and college attendance. College Student Journal. http://findarticles.com/p/articles/mi_m0FCR/is_4_35/ai_84017196/pg_ 8/?tag=mantle_skin;content

Gove, W. R., \& Mongione, T. W. (1983). Social roles, sex roles and psychological distress: Additive and interactive models of sex differences. Journal of Health and Social Behavior, 24, 300-312.

Goldstine, H. S. (1982). Fathers' absence and cognitive development of 12-17 year olds. Psychological Reports, 51, 843- 848; Nord, C., \& West, J. (2001). Fathers' and mothers' involvement in their children's schools by family type and resident status [On-line]. Available: http://nces.ed.gov/pubsearch/pubsinfo.asp?pubid=2 001032

Krohn, F., \& Bogan, Z. (Dec 2001). The effects absent fathers have on female development and college attendance. College Student Journal, 35(4), 598.

Li, L.W. and Seltzer, M.M. (2005). Relationship Quality with Parent, Daughter Role Salience, and Self-Esteem of Daughter Caregivers. Marriage \& Family Review (The Haworth Press, Inc.) 37(1/2), pp. 63-82

Menning, C. (2006). Nonresident fathering and school failure. Journal of Family Issues, 27, 1356-1382. In Nielsen.L (2012) Father-Daughter Relationships: Contemporary Research and Issues. Routledge, Taylor \& Francis Group 711 Third Avenue New York, NY 10017.

Nielsen, L. (2007, March 1). College daughters' relationships with their fathers: A 15 year study. College Student Journal, 41(1), 112-121. Retrieved January 29, 2009, from ERIC database. In Goosen, C. (2009). The Perceived Influence of a Father on His Daughter's Development. Undergraduate Research Journal for the Human Sciences, vol. 8.

Olweus, D. (1993). Bullying at School: what we know and what we can do. Cambridge, MA: Blackwell. ED 384437.

Ozer, E. M., Barnett, R. C., Brennan R. T., \& Sperling, J. (1998). Does child care involvement increase or decrease distress among dualearner couples? Women's Health, 4 (4), 285-311.

Pleck, J. H. (1997). Paternal involvement: levels, sources, and consequences. In M. Lamb (Ed.), The role of the father in child development (pp. 66-103). New York: John Wiley \& Sons, Inc

Pruett, K. (2000). Father-need. New York, NY: Broadway Books; Sternberg, K. J. (1997) Goldstine, H. S. (1982). Fathers' absence and cognitive development of 12-17 year olds. Psychological Reports, 51, 843-848; Nord, C., \& West, J. (2001). http://portal. hud.gov/hudportal/documents/huddoc?id=rfdtoolkit.pdf

Pedersen, F. A., Anderson, B. J., \& Kain, R. L. (1980). Parent-infant and husband wife interactions observed at age five months. In F. Pedersen (Ed.), The father-infant relationship: Observational studies in the family setting (pp. 71-86). New York: Praeger.

Snarey, J. (1993). How fathers care for the next generation. : A four-decade study. Cambridge, MA: Harvard University Press 